\title{
Differential expression of genes in adipose tissue of first-lactation dairy cattle ${ }^{1}$
}

\author{
J. M. Sumner-Thomson, ${ }^{\star}$ J. L. Vierck, $\dagger$ and J. P. McNamara ${ }^{2}$ \\ *Department of Agricultural, Food and Nutritional Sciences, University of Alberta, Edmonton T6G 2P5, Canada \\ †Department of Animal Sciences, Washington State University, Pullman 99164-6351
}

\begin{abstract}
Adipose tissue metabolism is an essential factor in establishment of a successful lactation, and we have a good understanding of changes in metabolic flux in relation to lactation, parity, and diet. However, the mechanisms of control of flux are less well understood. To continue our investigations into the control of adipose tissue metabolism, we conducted a transcriptomic analysis of adipose tissue of dairy cattle in late pregnancy and early lactation. Our objective was to determine the changes in gene expression in adipose tissue between $30 \mathrm{~d}$ prepartum and $14 \mathrm{~d}$ in milk in first-lactation animals, and to determine if changes in expression were related to practical production variables. Animals were Holstein heifers fed the same diet to National Research Council requirements, and adipose tissue was biopsied at $30 \mathrm{~d}$ prepartum and 14 DIM. Total RNA was extracted and used to determine gene expression on a bovine gene array. Genes that code for proteins controlling fatty acid transport were highly expressed including fatty acid binding proteins (FABP 4 and $F A B P 5)$ and lipoprotein lipase. Among those genes increasing in expression were those controlling lipolysis, including ADRB2 (52\%) and LIPE (23\%). Many genes coding for enzymes controlling lipogenesis decreased, including SREBP (-25\%), TSHSP14 (-30.8\%), LPL $(-48.4 \%)$, and $A C A C A(-63.9 \%)$. This gene expression array analysis in adipose tissue of lactating dairy cattle identifies several key genes that are components of the adaptation to lactation that can be incorporated into models of nutritional efficiency and may be amenable to genetic or dietary manipulation.
\end{abstract}

Key words: lactation, adipose, metabolic control, transcriptome

Received May 17, 2010.

Accepted September 30, 2010.

${ }^{1}$ This project was supported by National Research Initiative Competitive Grant no. 2007-35206-17841 from the USDA Cooperative State Research, Education, and Extension Service and the Agricultural Research Center, Washington State University. This paper is published in conjunction with the NC-1040 CREES Regional Research Project "Metabolic Relationships in Lactating Dairy Cattle."

${ }^{2}$ Corresponding author: mcnamara@wsu.edu

\section{INTRODUCTION}

One of the first studies on adipose tissue metabolism in pregnant and lactating dairy cattle demonstrated changes in enzymes controlling lipogenesis and lipolysis during lactation (Shirley et al., 1973). This work was confirmed and extended to identify more-specific adaptations in metabolic flux and enzyme activity (Baldwin et al., 1973; Yang and Baldwin, 1973). Many studies on adipose since then have defined metabolic adaptations to lactation (see McNamara, 1994, 2004; McNamara and Hillers, 1989; Vernon, 2003). From these studies, we learned that cows of greater genetic merit for milk production had increased adipose tissue lipolysis, an increased response to $\beta$-adrenergic stimulation, increased activity of hormone sensitive lipase (LIPE), and decreased lipogenesis compared with averagegenetic-merit animals (McNamara and Hillers, 1989; Smith and McNamara, 1990; see also several references in McNamara, 1994; 2004).

The adaptations of decreased lipogenesis and increased lipolysis to lactation and genetic merit can be attenuated by dietary energy intake (McNamara, 1994; Parmley and McNamara, 1996; Vernon, 2003). During early lactation, a decrease in expression of acetyl-CoA carboxylase and lipoprotein lipase, and a diminished response to insulin are common control adaptations for lipogenesis (Pape et al., 1988; Martin-Hidalgo et al., 1994; Travers et al., 1997; Drackley et al., 2006). Recently we demonstrated that the mRNA abundance for 5 genes for that control lipolysis ( $3 \beta$-adrenergic receptors, hormone sensitive lipase, and perilipin, PLIN) increased in expression in adipose tissue of dairy cattle during lactation (Sumner and McNamara, 2007). Other recent work suggests involvement of another enzyme, adipose tissue triacylglycerol lipase, in control of chronic lipolysis, and this may play a role in metabolic control as well (Langin et al., 2005; Pinent et al., 2008).

We now also understand that adipose tissue plays a more important role than simply energy storage. The tissue is a source of IGF-I and leptin, and it expresses several immune function proteins, inflammatory and antiinflammatory agents, and cytokines (Loor et al., 
2006; Prokesch et al., 2009; Thering et al., 2009). Adipose tissue contributes to the inflammation of metabolic syndrome and diabetes in animal models and humans (Bernabucci et al., 2006; Baranova et al., 2007; Teran-Garcia and Bouchard, 2007). Both of these disease states have similarities to the increased lipolysis, insulin resistance, and increased inflammation of early lactation. Recent studies on adipose tissue gene expression in other species demonstrate a large number of changes in expression caused by several genetic and environmental influences (Swierczynski, 2006; Wang et al., 2006; de Souza Batista et al., 2007).

Recent work extends our knowledge of metabolic control in dairy cattle through use of transcriptomic arrays (Mukesh et al., 2010). When used in a focused research program bounded by knowledge on changes in metabolic flux, endocrine patterns, body composition, and production changes, transcriptomic analyses can be a powerful tool to answer questions of metabolic control as well as to find potentially important changes in gene transcription as yet undiscovered. Thus, as a continuation of our work on adipose tissue metabolic control, we conducted an initial analysis of gene expression in the adipose tissue of dairy cattle in late pregnancy and early lactation. We tested the hypothesis that one or more genes changed expression in adipose tissue due to the lactational state compared with that in late pregnancy, and that expression of some of these genes would be related to the milk production or genetic merit of the animals. We also wanted to use a pathway analysis tool to better identify the patterns of changes in expression of genes known to control key metabolic pathways and to identify other genes that may control cellular processes, inflammation, or immunity potentially important to a successful lactation.

\section{MATERIALS AND METHODS}

Holstein dairy cattle from the Washington State University Knott Dairy Center (Pullman) were used in this analysis and were housed and fed in accordance with USDA guidelines and protocols approved by the Washington State University Institutional Animal Care and Use Committee (protocol \# 3364). Twenty firstlactation animals were selected from the top $25 \%$ of the herd for milk production based upon the sire predicted transmitting ability for milk records. The animals calved from May 2007 through November 2007. Of the 20 animals, 11 provided sufficient quality RNA to be used for gene chip array analysis.

All animals were fed the same ration during the dry period, starting at approximately $21 \mathrm{~d}$ prepartum, formulated to meet or exceed nutrient requirements as recommended by NRC (2001; Table 1). During lacta-
Table 1. Dietary composition of dry and lactating cow rations

\begin{tabular}{lcc}
\hline Item & Dry & Lactating \\
\hline Ingredient, \% of DM & & \\
Alfalfa haylage & 44.0 & 26.26 \\
Orchardgrass hay & 44.0 & \\
Alfalfa hay & & 21.74 \\
Whole cottonseed & 12.0 & 9.68 \\
Concentrate mix & & 42.32 \\
Concentrate composition, \% & 76.0 & 52.5 \\
Corn & & 22.25 \\
Barley & 8.0 & 8.9 \\
Peas & 11.0 & 8.9 \\
Soybean meal & 1.0 & 2.5 \\
Megalac & 1.0 & 1.0 \\
Limestone & & 0.75 \\
Trace mineral salt & 1.0 & 2.0 \\
Sodium bicarbonate & 0.1 & 0.015 \\
Seleno yeast & & 0.4 \\
Magox & 0.4 & 0.1 \\
4-Plex & & 0.05 \\
Vitamin D premix & 0.1 & 0.025 \\
Vitamin A premix & & 0.01 \\
Vitamin E premix & & 0.6 \\
Yeast XP & & \\
Chemical composition & & \\
DM, \% as fed & 68.0 & 58.0 \\
CP, \% of DM & 12.9 & 18.5 \\
NDF, \% of DM & 37.1 & 24.2 \\
ADF, \% of DM & 26.3 & 19.6 \\
\hline
\end{tabular}

${ }^{1}$ Arm \& Hammer Animal Nutrition, Church \& Dwight Co. Inc., Princeton, NJ.

${ }^{2}$ Zinpro Corporation, Eden Prairie, MN.

${ }^{3}$ Diamond V Mills, Cedar Rapids, IA.

${ }^{4}$ From chemical analyses of components.

tion, all animals were fed the same ration to requirements (NRC, 2001; Table 1). Intake was not measured in this study, because we simply wanted to understand what, if any, changes were happening due to the transition to lactation, to change in body fat, and to actual milk production.

Adipose tissue biopsies, BW, BCS, and blood were collected at $30 \mathrm{~d}$ prepartum and 14 DIM as detailed in Sumner and McNamara (2007). Adipose tissue biopsies were collected under local anesthesia from the tailhead region (Sumner and McNamara, 2007).

\section{Extraction of RNA}

Adipose tissue samples were placed immediately into Trizol reagent, homogenized, and kept on ice until RNA was extracted within $2 \mathrm{~h}$. Total RNA was extracted with the RNeasy Lipid Tissue Midi Kit (Qiagen, Valencia, CA), and the RNA samples were resuspended in RNase-free water. The quality and quantity of RNA was determined using spectroscopy ratios at $260 \mathrm{~nm} / 280$ $\mathrm{nm}$ and also by denaturing gel electrophoresis $[1.2 \%$ agarose, $0.66 M$ formaldehyde, $20 \mathrm{~m} M 3$-( $N$-morpholino) propanesulfonic acid (MOPS), $8 \mathrm{~m} M$ sodium acetate, 
and $1 \mathrm{~m} M$ EDTA) and examination of the $28 \mathrm{~S}$ and $18 \mathrm{~S}$ ribosomal bands after ethidium bromide staining.

The microarray analysis (probe labeling, hybridization, and scanning) was performed using Affymetrix GeneChip Bovine Genome Array (Affymetrix, Santa Clara, CA) following the manufacturer's instruction at the Washington State University Microarray Core Facility. Briefly, $5 \mu \mathrm{g}$ of total RNA from each tissue sample was first reverse transcribed to single-stranded cDNA using a $\mathrm{T} 7$ promoter-oligo $(\mathrm{dT})$ primer. The double-stranded cDNA were then synthesized using T4 DNA polymerase and used as a template for in vitro transcription to produce the biotinylated cRNA in the presence of T7 RNA polymerase. The full-length biotinylated cRNA were fragmented into 35- to 200-bp fragments and then hybridized to GeneChip Bovine Genome Arrays for $16 \mathrm{~h}$ at $45^{\circ} \mathrm{C}$ in a rotating Affymetrix GeneChip hybridization oven 320. After hybridization, arrays were washed and stained with streptavidinphycoerythrin on an automated Affymetrix GeneChip Fluidic Station F450 station. The arrays were scanned with an Affymetrix GeneChip Scanner 2700 and the images quantified using Affymetrix GeneChip Operating Software (GCOS, Affymetrix). All genes are referred to using the NCBI/HUGO approved gene symbols (http://www.genenames.org/).

\section{Experimental Design and Analysis}

The study to determine whether genes changed in expression in adipose tissue of dairy cattle from postpartum to prepartum was a completely random design with day of sampling as the fixed effect (Steele and Torrie, 1980; Sumner and McNamara, 2007). Signal strength and changes in expression were subjected to statistical analysis within the GeneSpring program (Agilent Technologies, Santa Clara, CA) following the design above. The gene chip analysis software filter for gene expression was as follows: a presence call was based on signal strength of 50 or higher, with the normalization set to a signal of 125 (GCOS). Array quality was determined using a combination of $3^{\prime} / 5^{\prime}$ bias for GAPDH and $\beta$-actin with a value $<3.0$; the percentage of genes expressed as present was greater than $60 \%$, and the noise background less than 50 units (GCOS).

For some of the analyses, array data were normalized and $\log 2$ transformed using GeneSifter software (GeneSifter.Net, VizX Laboratories, Seattle, WA). Pairwise statistical analyses of array data were performed by Student's $t$-test using GeneSifter software. Array data for significantly differentially expressed genes were overlaid onto ontological pathways (http://www.geneontology. org/; Ashburner et al. 2000) using GeneSifter software.
$z$-Scores were calculated in GeneSifter using the following formula:

$$
\begin{gathered}
\text { Score }=[r-\mathrm{n}(R / N)] /(\sqrt{ }[\mathrm{n}(R / N)] \times(1-R / N) \\
\times\{1-[(\mathrm{n}-1) /(N-1)]\}),
\end{gathered}
$$

where $R=$ total number of genes meeting selection criteria, $N=$ total number of genes measured, $r=$ number of genes meeting selection criteria with the specified gene ontology $(\mathbf{G O})$ term, and $\mathrm{n}=$ total number of genes measured with the specific GO term. $z$-Scores $>2$ or $<-2$ were considered significant (Cox, et al., 2006; Doniger et al. 2003). The $P$-values (pre- vs. postpartum) are reported and deemed significant at $(P<0.05)$.

\section{RESULTS AND DISCUSSION}

\section{Animal-Level Data}

In the first month of lactation, animals produced $32 \mathrm{~kg} / \mathrm{d}$ of milk with a range from 8 to $82 \mathrm{~kg} / \mathrm{d}$. For the first 60 DIM, animals were producing $29 \mathrm{~kg} / \mathrm{d}$ of milk with a range from 11 to $52 \mathrm{~kg} / \mathrm{d}$ (Table 2), and their eventual 305-d mature-equivalent milk yield was $>13,000 \mathrm{~kg}$. This provided a wide range of production levels to ask questions about the relationship of mRNA abundance in adipose tissue to milk production. Feed intake was not measured, but from a data set of animals measured immediately after this study in our herd (May 2008 through April 2009), DMI was 11.5 (SEM 0.17 ) $\mathrm{kg} / \mathrm{d}$ from 21 to $7 \mathrm{~d}$ prepartum and 16.7 (SEM 0.22 ) $\mathrm{kg} / \mathrm{d}$ from 7 to 21 DIM (Rocco et al., 2010). Body weights and BCS changed in early lactation as expected for first-lactation animals (Table 2), with a range from 4.1 to $-51.7 \mathrm{~kg}$ of $\mathrm{BW}$ change and 0.0 to -1.0 change in BCS.

\section{Transcriptomic Array Analyses}

For the expression arrays, 433 genes showed increased expression by 2 -fold or more; 1,080 showed increased expression of more than 50\%; 22,640 increased within $\pm 25 \%$; 307 decreased by more than $50 \%$; and 30 decreased by more than $75 \%$. Global pairwise analysis showed several global changes in genes involved in several metabolic processes (Table 3). Changes were expected and observed in genes controlling nutrient utilization. In addition to the expected changes, changes in gene expression were observed in processes and functions of adipose tissue metabolism that are less understood in dairy cattle. The pairwise analysis done here also revealed changes in several genes controlling 
Table 2. Production characteristics of first-lactation Holstein heifers used in the study

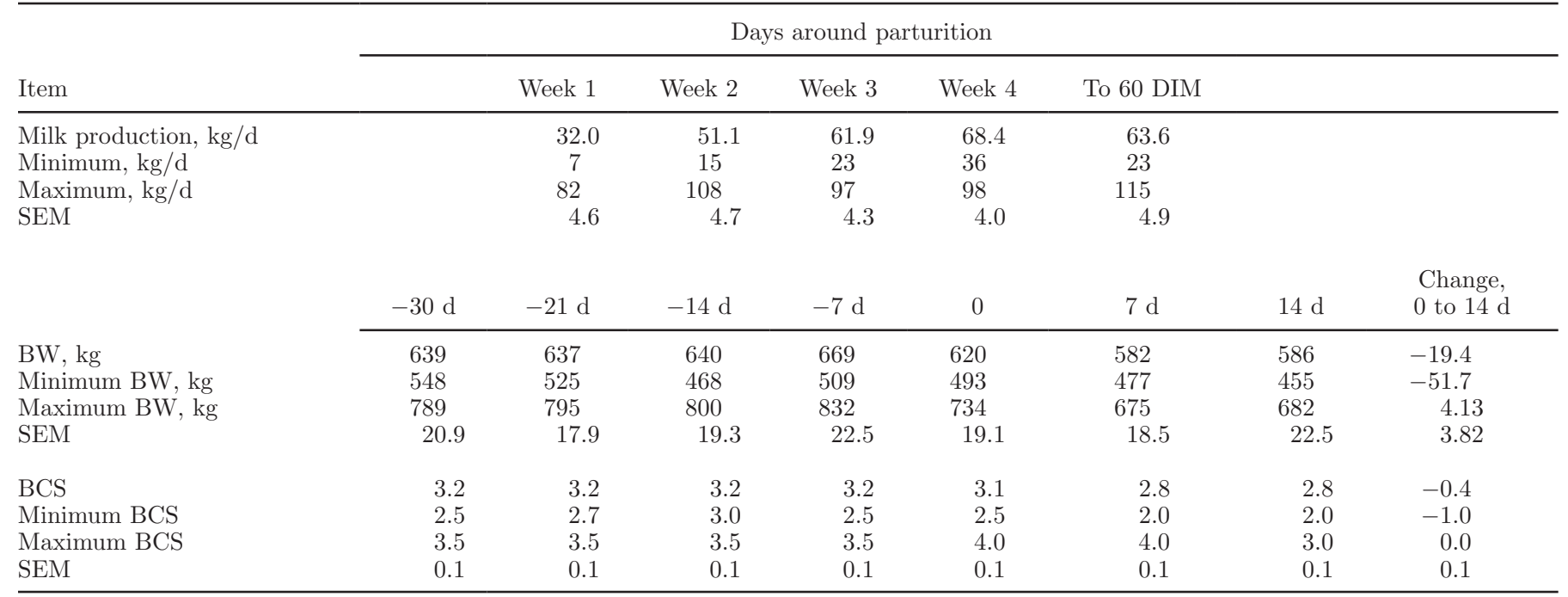

inflammatory and immune processes. For example, the bovine homolog of LPS-induced tumor necrosis factor- $\alpha$ (LPTL1) increased $50.0 \%(P<0.01)$; the BCL-2 adenovirus interacting protein (BNIP3) increased $75 \%$; serum amyloid A3 factor (SAA3) decreased by $42 \%(P$ $<0.09$ ) and chemokine (C-C motif) ligand 2 (CCL2) decreased by $42 \%(P<0.01)$. These changes may relate to potential immune and inflammatory function in early lactation.

Interestingly, strong z-scores were found for many genes involved in cellular remodeling and angiogenesis (Table 4), including increases in angiopoietin-like 4 (ANGPTL4) and BNIP3, and decreases in several control molecules including angiopoietin-2 (ANGPT2), msh homeobox protein (MSX1), and IGF-binding protein 6 (IGFBP6). It is not surprising to see a mix of increases and decreases in mRNA abundance of cellular remodeling and angiogenesis during this time, because adipose tissue is undergoing a dynamic response to simultaneous signals for increased lipid release and an increase in energy intake.

Further analysis of such data may help identify elements of control of adipose tissue function related to support of milk production. A full-scale analysis is beyond the scope of this paper, but interested readers can access Gene Expression Omnibus (GEO) online (http://www.ncbi.nlm.nih.gov/geo/query/acc.cgi?acc = GSE21535). The authors are happy to share any other data and analyses from this trial.

Several genes known to function in metabolic flux control increased or decreased from $30 \mathrm{~d}$ prepartum to 14 DIM (Tables 3-5). As expected, expression of many genes that code for enzymes and proteins that control anabolic reactions, especially fatty acid synthesis, de- creased remarkably. These genes included lipoprotein lipase $(L P L ;-48 \%)$, acetyl CoA carboxylase $(A C A C A$; -60 to $-63 \%)$, and ATP-citrate lyase $(A C L Y,-18 \%)$. Even more interesting was that the upstream regulators of anabolic control also decreased, including thyroid stimulating hormone receptor spot $14(31 \%)$, and steroid response element binding protein (25\%). A reduced expression of acetyl CoA carboxylase mRNA was reported several years ago (Pape et al., 1988); however, for many of these genes, this is the first report of gene expression in adipose tissue of dairy cattle during lactation. These data will allow us to improve our models of metabolic control of nutrient use (McNamara, 2004; 2010), and further quantify control of metabolic flux in support of lactation.

Previously we reported coordinated increases in rates of lipolysis, both basal and stimulated, in adipose tissue of dairy cattle (McNamara and Hillers, 1989; see also references in McNamara, 2004; McNamara and Valdez, 2005; Sumner and McNamara, 2007). Recently we measured an increase in the mRNA for ADRB2, LIPE, and $P L I N$ in adipose tissue; however, expression reached the highest level at peak lactation around 90 DIM (Sumner and McNamara, 2007). Lipolysis is closely related to milk production regardless of overall energy balance, so it is not surprising that gene expression is highest when the need for milk fat is greatest and when the amount of adipose tissue is already markedly reduced. In addition, the body of knowledge on control of lipolysis is that a major element of control is posttranslational through activation of ADRB2 by norepinephrine from the sympathetic nervous system (Travers et al., 1997; McNamara, 2004). Until now, however, we have not had a quantitative understanding of how much of the 
adaptation to lactation in lipolysis are accounted for by transcriptional change or post-translational control.

The present work adds some clarity to the situation. Expression of ADAB2 increased $52 \%$ from $30 \mathrm{~d}$ prepartum to 14 DIM (Table 6). Expression of LIPE increased about $23 \%$, with a large amount of variation among animals. In this study, the mRNA levels for PLIN did not change in early lactation. In Sumner and McNamara (2007), a large increase in expression was observed, but at 90 DIM. Recently it was determined, consistent with our previous study (Sumner and McNamara, 2007) that PLIN mRNA as well as unphosphorylated and phosphorylated PLIN is expressed in adipose tissue of lactating cows (Elkins and Spurlock, 2009). Such find-

Table 3. Global analysis of transcriptomic array from subcutaneous adipose tissue in first-lactation Holsteins $30 \mathrm{~d}$ prepartum and $14 \mathrm{~d}$ postpartum

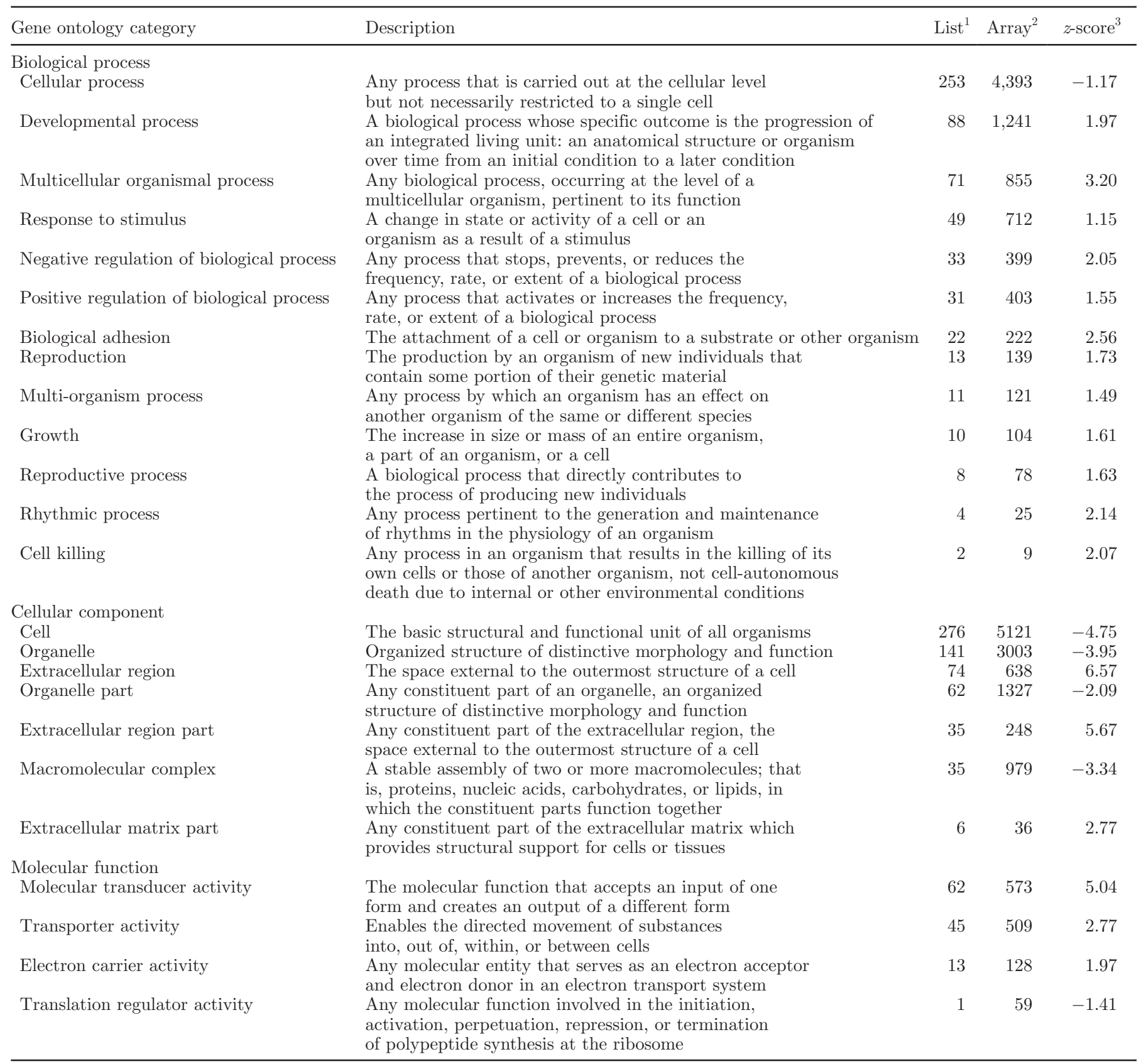

${ }^{1}$ Number of transcripts differentially expressed with a specific gene ontology term.

${ }^{2}$ Number of transcripts on the array matching a specific gene ontology term.

${ }^{3} \mathrm{An}$ enrichment score. A value $>2$ or $<-2$ is significant $(P<0.05)$. 
Table 4. Functional analysis of transcriptomic array from subcutaneous adipose tissue in first-lactation Holsteins $30 \mathrm{~d}$ prepartum and $14 \mathrm{~d}$ postpartum for elements involved in metabolism

\begin{tabular}{|c|c|c|c|}
\hline Process & $\begin{array}{l}\text { Example } \\
\text { genes }\end{array}$ & Effect & $P$-value \\
\hline \multirow[t]{5}{*}{ Carbohydrate metabolism } & $G B G T 1$ & $\downarrow$ & 0.004 \\
\hline & GNPDA2 & $\downarrow$ & 0.001 \\
\hline & $D S E$ & $\downarrow$ & 0.010 \\
\hline & $L E P$ & $\downarrow$ & 0.004 \\
\hline & B3GNT8 & $\downarrow$ & 0.001 \\
\hline \multirow[t]{7}{*}{ Lipid metabolism } & PRKAG1 & $\downarrow$ & 0.008 \\
\hline & $S C D$ & $\downarrow$ & 0.008 \\
\hline & $C Y P 11 A 1$ & $\downarrow$ & 0.003 \\
\hline & РPAP2B & $\downarrow$ & 0.004 \\
\hline & PRKAG1 & $\downarrow$ & 0.008 \\
\hline & PTGIS & $\downarrow$ & 0.010 \\
\hline & PTGS1 & $\downarrow$ & 0.007 \\
\hline \multirow[t]{5}{*}{ Oxidation reduction } & $\mathrm{LOXL4}_{4}$ & $\downarrow$ & $<0.001$ \\
\hline & $M A O B$ & $\downarrow$ & 0.001 \\
\hline & $C Y P 4 V 2$ & $\uparrow$ & 0.009 \\
\hline & $\mathrm{TH}$ & $\downarrow$ & 0.004 \\
\hline & NDUFB2 & $\downarrow$ & $<0.001$ \\
\hline \multirow[t]{5}{*}{ Proteolysis } & DKFZP586H2123 & $\uparrow$ & $<0.001$ \\
\hline & $A D A M T S_{4}$ & $\uparrow$ & 0.003 \\
\hline & RNPEPL1 & $\uparrow$ & 0.008 \\
\hline & $C P X M 2$ & $\downarrow$ & 0.008 \\
\hline & TPSB1 & $\downarrow$ & 0.002 \\
\hline
\end{tabular}

ings are consistent with the idea that changes in both expression and posttranslational modification are critical in control of lipolysis in lactating dairy cattle.

Thus from this study, we hypothesize that the majority of control of lipolysis is exerted posttranslationally, but that increased expression of the genes may contribute some control to increased lipolysis during lactation. This makes sense if we compare the more involved regulation of a series of metabolic reactions involved in lipogenesis to the more singular mechanism (one rate-limiting enzyme, LIPE) for lipolysis. The need for very rapid changes in lipolysis to a host of environmental responses suggests utility in having sufficient inactive protein constitutively expressed and ready to respond to endocrine and neurocrine changes. This is also consistent with what we found in the rodent model of increased sympathetic nervous system activity in adipose tissue during lactation (McNamara and Murray, 2001).

Another novel finding from this work that relates to control of lipolysis is in the expression of the caveolar proteins, caveolin-1 and caveolin-2 (CAV1 and CAV2; Table 6), which both decreased in early lactation $(P$ $<0.02)$. These proteins are part of the control system

Table 5. Functional analysis of transcriptomic array from subcutaneous adipose tissue in first-lactation Holsteins $30 \mathrm{~d}$ prepartum and $14 \mathrm{~d}$ postpartum for elements involved in cellular or tissue remodeling

\begin{tabular}{llcc}
\hline \multirow{2}{*}{ Term } & Example & & \\
& genes & Effect & $P$-value \\
\hline Angiogenesis & ANGPTL4 & $\uparrow$ & 0.002 \\
& ANXA2 & $\downarrow$ & 0.008 \\
& BMP4 & $\downarrow$ & 0.000 \\
& ANGPT2 & $\downarrow$ & 0.001 \\
& PGF & $\downarrow$ & 0.001 \\
Actin filament organization & DBN1 & $\downarrow$ & 0.008 \\
Apoptosis & CIDEB & $\downarrow$ & 0.008 \\
& BNIP3 & $\uparrow$ & 0.009 \\
& RAD21 & $\uparrow$ & 0.007 \\
& MSX1 & $\downarrow$ & 0.008 \\
Positive regulation of cell proliferation & BTG1 & $\uparrow$ & 0.001 \\
& BCL2L14 & $\uparrow$ & 0.007 \\
Regulation of cell growth & OSR2 & $\downarrow$ & 0.008 \\
& CEBP & $\uparrow$ & 0.001 \\
& IGFBP6 & $\downarrow$ & 0.009 \\
& CDC42EP2 & $\downarrow$ & 0.008 \\
\hline
\end{tabular}


Table 6. Changes in metabolic control element genes in adipose tissue of dairy cattle from $30 \mathrm{~d}$ prepartum to $14 \mathrm{~d}$ postpartum ${ }^{1}$

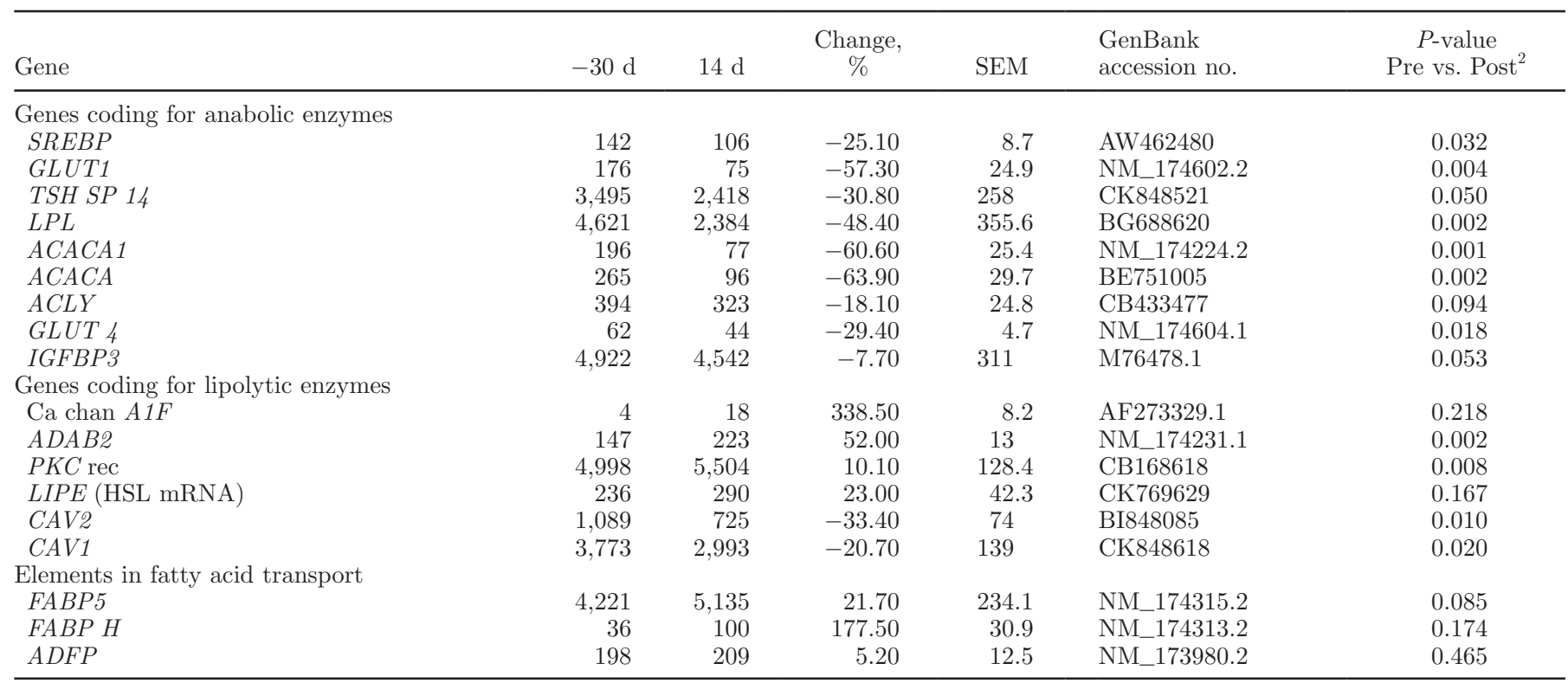

${ }^{1}$ Data are average changes in gene expression (average signal = 125) on Affymetrix Gene Array analysis of bovine adipose tissue from 11 pairs of gene arrays.

${ }^{2}$ Pre $=30 \mathrm{~d}$ prepartum; Post $=14$ DIM.

for formation and utilization of triacylglycerol-rich lipid droplets (Cohen et al., 2004). Much attention has been focused on the control of LIPE and PLIN by catecholamine-induced phosphorylation, but it is now clear that control of lipolysis is also carried out by ATGL and the caveolin family of proteins (Cohen et al., 2004). These proteins are positively associated with storage of triacylglycerol and negatively associated with utilization; in short, a reduction in CAV1 and CAV2 is required for full activity of LIPE (Cohen et al., 2004). Thus, the data obtained are consistent with the role of these proteins in the massive restructuring of adipocytes in early lactation in dairy cattle.

\section{Relation of Transcriptomic Data with Animal Level Data}

In the study of systems biology, one usually tries to answer a question of the form "What is the quantitative contribution of one piece of the system to the overall function of the system?" In our case, we asked whether, and to what extent, the change in expression of a gene for a protein that controls a metabolic process in one organ (lipogenesis or lipolysis in adipose tissue) relates to the system-level output (milk production). In this study, we were able to confirm some previous results (Sumner and McNamara, 2007) and extend them to other control elements. As a general pattern, key regulatory elements in anabolic reactions were negatively associated with milk production, whereas elements controlling lipolysis were positively associated (Table 7). Considering the full system of the dairy cow, it is enlightening to identify that the well-known control elements for metabolic interactions in the supporting organ of the adipose tissue relate significantly to the end-product of milk production. It is not surprising that expression of control elements of adipose tissue anabolism is related inversely to milk production with a regression coefficient of 16 to $30 \%$. It is also not surprising that the 2 major control elements, ADAB2 and LIPE, are related to milk production in the range of 30 to $36 \%$, because a large proportion of milk fat must come from release of NEFA from triacylglycerol in the adipose tissue. In fact, if one uses the body of knowledge that approximately $50 \%$ of milk fat comes from released body fat and that expression of these 2 genes controlling lipolysis relate to 30 to $36 \%$ of overall milk production, it can be hypothesized that most control of supply of long-chain fatty acids to the mammary gland comes from an increase in expression of these 2 controllers of lipolysis.

The data presented here provide the first serious evidence of the strict link between mechanisms of control of adipose tissue gene transcription with milk production. These data confirm and extend the earlier observations of the relationships between adipose tissue lipogenesis and lipolysis with milk production in dairy cattle (McNamara and Hillers, 1989) and provide 
Table 7. Linear regression of the mean change from $30 \mathrm{~d}$ prepartum to 14 DIM in transcription signal in subcutaneous adipose tissue with mean milk production for the first 60 DIM in first-lactation Holsteins

\begin{tabular}{lcll}
\hline & \multicolumn{3}{c}{ Milk, kg/d } \\
\cline { 2 - 4 } Gene of interest & Intercept & Slope & $\mathrm{RSQ}^{1}$ \\
\hline Anabolic processes & & & \\
ACACA1 & 57.5 & -0.064 & 0.176 \\
ACLY & 61.8 & -0.045 & 0.26 \\
GLUT4 & 61.7 & -0.18 & 0.168 \\
Catabolic processes & & & \\
LIPE & 66.2 & 0.577 & 0.374 \\
ADAB2 & 56.9 & 0.106 & 0.301 \\
\hline
\end{tabular}

${ }^{1}$ Regression coefficient.

a framework for specific definition of the link between genomic, transcriptomic, and metabolic regulation of efficiency in the dairy cow. In the future, we can use these results to build useful gene expression maps to further explore this mechanism of metabolic adaptation and, eventually, improve specific selection for efficient dairy cattle.

\section{CONCLUSIONS}

A transcriptomics analysis of bovine adipose tissue from $30 \mathrm{~d}$ prepartum to $14 \mathrm{~d}$ in milk discovered several changes in mRNA abundance for several genes that control use of nutrients and metabolites, inflammation and immune processes, cellular synthesis and remodeling, and angiogenesis. The dynamic nature of adaptation to lactation by adipose tissue includes simultaneous changes in anabolic and catabolic processes, cell death and synthesis, and degradation and regrowth of the tissue bed, circulatory, and nervous structure. Anabolic processes are clearly downregulated systemically throughout the entire set of pathways, whereas gene transcription is not as important a contributor, quantitatively, to control of catabolic pathways, which are proportionally more under the control of posttranslational neural and hormonal control. Data collected can be used in the next generation of systems biology models of metabolic efficiency in the dairy cow.

\section{ACKNOWLEDGMENTS}

We thank Derek Pouchnik and Marina Savenkova of the Washington State University Gene Expression Core Laboratory, Pullman, and Christopher Schachtschneider and John Swain of the Washington State University Department of Animal Sciences for their excellent technical assistance.

\section{REFERENCES}

Ashburner, M., C. A. Ball, J. A. Blake, D. Botstein, H. Butler, J. M. Cherry, A. P. Davis, K. Dolinski, S. S. Dwight, J. T. Eppig, M.
A. Harris, D. P. Hill, L. Issel-Tarver, A. Kasarskis, S. Lewis, J. C. Matese, J. E. Richardson, M. Ringwald, G. M. Rubin, and G. Sherlock. 2000. Gene ontology: Tool for the unification of biology. The Gene Ontology Consortium. Nat. Genet. 25:25-29.

Baldwin, R. L. V, R. S. Reichl, S. Louis, N.E. Smith, Y.T. Yang, and E. Osborne. 1973. Effects of age, pregnancy, and lactation on rat, guinea pig, and cow adipose enzyme activities and cow adipose metabolism. J. Dairy Sci. 56:340-349.

Baranova, A., M. Randhawa, M. Jarrar, and Z. M. Younossi. 2007. Adipokines and melanocortins in the hepatic manifestation of metabolic syndrome: Nonalcoholic fatty liver disease. Expert Rev. Mol. Diagn. 7:195-205.

Bernabucci, U., L. Basirico, N. Lacetera, P. Morera, B. Ronchi, P. A. Accorsi, E. Seren, and A. Nardone. 2006. Photoperiod affects gene expression of leptin and leptin receptors in adipose tissue from lactating dairy cows. J. Dairy Sci. 89:4678-4686.

Cohen, A. W., B. Razani, W. Schubert, T. M. Williams, X. B. Wang, P. Iyengar, D. L. Brasaemle, P. E. Scherer, and M. P. Lisanti. 2004. Role of caveolin-1 in the modulation of lipolysis and lipid droplet formation. Diabetes 53:1261-1270.

Cox, L. A., N. Schlabritz-Loutsevitch, G. B. Hubbard, M. J. Nijland, T. J. McDonald, and P. W. Nathanielsz. 2006. Gene expression profile differences in left and right liver lobes from mid-gestation fetal baboons: A cautionary tale. J. Physiol. 572:59-66.

de Souza Batista, C. M., R. Z. Yang, M. J. Lee, N. M. Glynn, D. Z. Yu, J. Pray, K. Ndubuizu, S. Patil, A. Schwartz, M. Kligman, S. K. Fried, D. W. Gong, A. R. Shuldiner, T. I. Pollin, and J. C. McLenithan. 2007. Omentin plasma levels and gene expression are decreased in obesity. Diabetes 56:1655-1661.

Doniger, S. W., N. Salomonis, K. D. Dahlquist, K. Vranizan, S. S. Lawlor, and B. R. Conklin. 2003. MAPPFinder: Using Gene Ontology and GenMAPP to create a global gene-expression profile from microarray data. Genome Biol. 4:R7.

Drackley, J. K., S. S. Donkin, and C. K. Reynolds. 2006. Major advances in fundamental dairy cattle nutrition. J. Dairy Sci. 89:1324-1336.

Elkins, D. A., and D. M. Spurlock. 2009. Phosphorylation of perilipin is associated with indicators of lipolysis in Holstein cows. Horm. Metab. Res. 41:736-740.

Langin, D., A. Dicker, G. Tavernier, J. Hoffstedt, A. Mairal, M. Ryde'n, E. Arner, A. Sicard, C. M. Jenkins, N. Viguerie, V. van Harmelen, R. W. Gross, C. Holm, and P. Arner. 2005. Adipocyte lipases and defect of lipolysis in human obesity. Diabetes 54:3190-3197.

Loor, J. J., H. M. Dann, N. A. Guretzky, R. E. Everts, O. R. Oliveira, C. A. Green, N. B. Litherland, S. L. Rodriguez-Zas, H. A. Lewin, and J. K. Drackley. 2006. Plane of nutrition prepartum alters hepatic gene expression and function in dairy cows as assessed by longitudinal transcript and metabolic profiling. Physiol. Genomics 27:29-41.

Martin-Hidalgo, A., C. Holm, P. Belfrage, M. C. Schotz, and E. Herrera. 1994. Lipoprotein Lipase activity and mRNA in rat adipose tissue during pregnancy. Am. J. Physiol. 266:E930-E935.

McNamara, J. P. 1994. Lipid metabolism in adipose tissue during lactation: a model of a metabolic control system. J. Nutr. 124(Suppl.):1383S-1391S.

McNamara, J. P. 2004. Research, improvement and application of mechanistic, biochemical, dynamic models of metabolism in lactating dairy cattle. Anim. Feed Sci. Technol. 112:155-176.

McNamara, J. P. 2010. Integrating transcriptomic regulation into models of nutrient metabolism in agricultural animals. Pages $27-$ 38 in Proc. Int. Symp. Energy and Protein Metabolism. G. Matteo Crovetto, ed. EAAP Publication 127. Wageningen Academic Publishers, Wageningen, the Netherlands.

McNamara, J. P., and J. K. Hillers. 1989. Regulation of bovine adipose tissue metabolism during lactation 5. Relationships of lipid synthesis and lipolysis with energy intake and utilization. J. Dairy Sci. 72:407-418.

McNamara, J. P., and C. E. Murray. 2001. Sympathetic nervous system activity in adipose tissues during pregnancy and lactation of the rat. J. Dairy Sci. 84:1382-1389. 
McNamara, J. P., and F. Valdez. 2005. Adipose tissue metabolism and production responses to calcium propionate and chromium propionate. J. Dairy Sci. 88:2498-2507.

Mukesh, M., M. Bionaz, D. E. Graugnard, J. K. Drackley, and J. J. Loor. 2010. Adipose tissue depots of Holstein cows are immune responsive: Inflammatory gene expression in vitro. Domest. Anim. Endocrinol. 38:168-178.

National Research Council. 2001 Nutrient Requirements of Dairy Cattle. 10th rev. ed. National Academy Press, Washington, DC.

Pape, M. E., F. Lopez-Casillas, and K. H. Kim. 1988. Physiological regulation of acetyl-CoA carboxylase gene expression: Effects of diet, diabetes, and lactation on acetyl-CoA carboxylase mRNA. Arch. Biochem. Biophys. 267:104-109.

Parmley, K. L. S., and J. P. McNamara. 1996. Lipid metabolism in adipose tissue of pigs fed varying amounts of energy. J. Nutr. 126:1644-1656.

Pinent, M., H. Hackl, T. R. Burkard, A. Prokesch, C. Papak, M. Scheideler, G. Hämmerle, R. Zechner, Z. Trajanoski, and J. G. Strauss. 2008. Differential transcriptional modulation of biological processes in adipocyte triglyceride lipase and hormone-sensitive lipase-deficient mice. Genomics 92:26-32.

Prokesch, A., H. Hackl, R. Hakim-Weber, S. R. Bornstein, and Z. Trajanoski. 2009. Novel insights into adipogenesis from omics data. Curr. Med. Chem. 16:2952-2964.

Rocco, S., G. Duncan, J. Kay, R. Bose, J. L Vierck, and J. P. McNamara. 2010. Regulation of adipose tissue metabolism by coordinated changes in gene transcription during the transition period. J. Dairy Sci. 93(E-suppl. 1):235. (Abstr.)

Shirley, J. E., R. S. Emory, E. M. Convey, and W. D. Oxender. 1973 Enzymic changes in bovine adipose and mammary tissue, serum and mammary tissue hormonal changes with initiation of lactation. J. Dairy Sci. 56:569-574.

Smith, T. R., and J. P. McNamara. 1990. Regulation of bovine adipose tissue metabolism during lactation 6. Cellularity and hormone sen- sitive lipase activity as affected by genetic merit and energy intake. J. Dairy Sci. 73:772-783.

Steele, R. G. D., and J. H. Torrie. 1980. Principles and Procedures of Statistics: A Biometrical Approach. 2nd ed. McGraw-Hill, New York, NY.

Sumner, J. M., and J. P. McNamara. 2007. Expression of key genes controlling lipolysis in adipose tissue of Holstein dairy cattle during the dry period and lactation. J. Dairy Sci. 90:5237-5246.

Swierczynski, J. 2006. Leptin and age-related down-regulation of lipogenic enzymes gene expression in rat white adipose tissue. J Physiol. Pharmacol. 57(Suppl. 6):85-102.

Teran-Garcia, M., and C. Bouchard. 2007. Genetics of the metabolic syndrome. Appl. Physiol. Nutr. Metab. 32:89-114.

Thering, B. J., D. E. Graugnard, P. Piantoni, and J. J. Loor. 2009. Alterations in adipose tissue lipogenic gene networks due to lipid feeding and milk fat depression in lactating cows. J. Dairy Sci. 92:4290-4300.

Travers, M. T., R. G. Vernon, and M. C. Barber. 1997. Repression of the acetyl-CoA carboxylase gene in ovine adipose tissue during lactation: the role of insulin responsiveness. J. Mol. Endocrinol. 19:99-107.

Vernon, R. G. 2003. Adipose tissue: An expanding role in the regulation of energy metabolism. Pages 451-464 in Progress in Research on Energy and Protein Metabolism. W. B. Souffrant and C. C. Metges, ed. Wageningen Academic Publishers, Wageningen, the Netherlands.

Wang, H., H. Li, Q. Wang, Y. Wang, H. Han, and H. Shi. 2006. Microarray analysis of adipose tissue gene expression profiles between two lines of chicken breeds. J. Biosci. 31:565-573.

Yang, Y. T., and R. L. Baldwin V.. 1973. Lipolysis in isolated cow adipose cells. J. Dairy Sci. 56:366-374. 